\title{
Design and Analysis of Truck Chassis
}

\author{
Giridhara V E \\ M. Tech Student,Department of Mechanical Engineering, \\ Akshaya institute of Technology, Tumakuru, Karnataka \\ Dr.Irfan G \\ HOD, Department of Mechanical Engineering \\ Akshaya institute of Technology, Tumakuru, Karnataka \\ Lohitesh jaga Kumar \\ Assistant Professor, Department of Mechanical Engineering \\ Akshaya institute of Technology, Tumakuru, Karnataka
}

\begin{abstract}
The task point is to plan and investigation of a pioneer sort truck (TATA ACE model) frame. The Automotive frame is considered as the foundation of the vehicle. On suspension distinctive individuals are given to reinforce it and a vital thought in skeleton outline is additionally to have satisfactory twisting solidness for supporting the body and diverse parts of the vehicle. Likewise, it ought to be sufficiently unbending to withstand the stun, turn, vibration and different hassles. Quality and the solidness are the two critical criteria for the configuration of the skeleton. The cross part is additionally dissected for the redirection because of bowing. The chassis frame consists of side members attached with a series of cross members. And the design of the chassis would be taken in the CATIA V5 software, the design calculations are carried out with the IS standards. FEA is done on the modelled chassis using the NASTRAN PATRAN Workbench; the FEA is carryout for linear static analysis of the chassis. Also Stress analysis using Finite Element Method can be used to locate the critical point which has the highest stress. This critical point is one of the factors that may cause the failure. The outcomes demonstrated that the basic part was at the mounting section of the tire furthermore at the front part of the skeleton. Result acquired after the scientific methodology for the suspension shaft as far as it anxiety advancement is roughly nearer to the FEA values.
\end{abstract}

KEY WORDS:- Chassis, Catia, Nastran-Patran, FEA.

\section{INTRODUCTION}

The body shapes the foundation of the landfill truck and its central capacity is to securely convey the most extreme burden, whether the vehicle is in static or element condition. There are a few favourable circumstances of rough terrain vehicles undercarriage over different case. It experiences some real detriments like overwhelming weight, weakness disappointment and welding splits. With the assistance of recreation devices like limited component technique, the degree of the impacts of undercarriage info conditions can undoubtedly be assessed with least test cost. As a test study, a 3-D limited component model was produced to anticipate the complete static hassles and weakness life of the high quality basic suspension, decide the weights on the case. Principle goal is to decide the static burdens characterized in pay burden and vehicle weight acting as response strengths was embraced for static burden condition. Another primary burden case is intended to check the nonappearance of any danger of exhaustion splits happening under the consolidated impact of the principle powers experienced amid running condition. These heap cases comprise of various burden situations subjecting skeleton including running of uneven track with $12 \%$ inclination, bend arrangement, rolling and ricocheting impact and track turn. The heap mixes are chiefly three cases like bowing, torsion and joined bowing and torsion.

\section{CHASSIS}




\section{International Journal of Innovations in Engineering and Technology (IJIET) \\ http://dx.doi.org/10.21172/ijiet.83.008}

The chassis is the structure to which is everything in a vehicle is connected. In a cutting edge vehicle, it is required to satisfy the accompanying capacities give mounting focuses to the suspensions, the controlling component, the motor and gearbox, the last drive, the fuel tank and the seating for the tenants, give unbending nature to precise taking care of, secure the inhabitants against outer effect. For a frame to satisfy these capacities, it ought to be sufficiently light to decrease inactivity and offer palatable execution. It additionally ought to likewise be sufficiently extreme to oppose exhaustion loads delivered because of connection between the driver, motor, control transmission and street conditions.

The body of the most vehicles ought to satisfy the accompanying prerequisites:

1) The body ought to be light.

2) It ought to have least number of segments.

3) It ought to give adequate space to travelers and baggage.

4) It ought to withstand vibrations while in movement.

5) It ought to offer least imperviousness to air.

6) It ought to be shoddy and simple in assembling.

7) It ought to be appealing fit as a fiddle and shading.

8) It ought to have consistently conveyed stack.

9) It ought to have long weariness life

10) It ought to give great vision and ventilation.

\section{LOAD DETERMINATION}

The load cases for this study are standardized cases and most of the calculations are carried out with the help of design data and other loading conditions. The main load acting on the chassis frame consists of engine, transmission, fuel tank, steering gearbox and cargo.

These are the loads that will be acting at a particular point throughout the chassis. The various systems mentioned above are mounted on various cross members, these members are then analyzed for the load acting at a certain point.

\begin{tabular}{|c|c|}
\hline Particulars & Weight(kg) \\
\hline Chassis self weight & 61.75 \\
\hline Engine Transmission Assembly & 105 \\
\hline Propeller Shaft & 5 \\
\hline Fuel Tank(Completely filled) & 35 \\
\hline Steering assembly & 28.5 \\
\hline Cabin weight(with driver) & 205 \\
\hline Battery & 6 \\
\hline Exhaust assembly & 7 \\
\hline
\end{tabular}


International Journal of Innovations in Engineering and Technology (IJIET)

http://dx.doi.org/10.21172/ijiet.83.008

\begin{tabular}{|c|c|}
\hline Tool box & 4 \\
\hline Radiator & 12 \\
\hline
\end{tabular}

Table 1 Weights of components

After examining the mounting of the above components and their weight distribution across the mounting points, final load acting on cross members and long members were calculated.

\section{DESIGN CALCULATIONS}

\section{BASIC CALCULATION}

Gross vehicle weight $=2250 \mathrm{Kg}=2250 \times 9.81=22072.5 \mathrm{~N}$

Kerb Weight $=1200 \mathrm{Kg}$

For the application of load on the chassis $=\frac{G_{V} V_{W} W}{2}$

$$
\begin{aligned}
& =\frac{22072.5}{2} \\
& =11036.25 \mathrm{~N}
\end{aligned}
$$

Capacity of the truck with $1.25 \%=11036.25 \times 1.25$

$$
=13795.31 \mathrm{~N}
$$

Uniformly Distributed Load (U.D.L) $=\frac{17795.31}{7800}=3.63 \mathrm{~N} / \mathrm{mm}$ 
Model: Tata ace

- Length of vehicle $=3800 \mathrm{~mm}$

- Width of vehicle $=1500 \mathrm{~mm}$

- Height of vehicle $=1845 \mathrm{~mm}$

- $\quad$ Wheelbase $=2100 \mathrm{~mm}$

- $\quad$ Track width-Front $=1300 \mathrm{~mm}$

- $\quad$ Track width-Front $=1320 \mathrm{~mm}$

- $\quad$ Material of chassis = structural steel

- Young's modulus $=2 \mathrm{e}+5$

- $\quad$ Poisson's ratio $=0.3$

- Length of chassis $=4201 \mathrm{~mm}$

- Width of chassis $=808 \mathrm{~mm}$
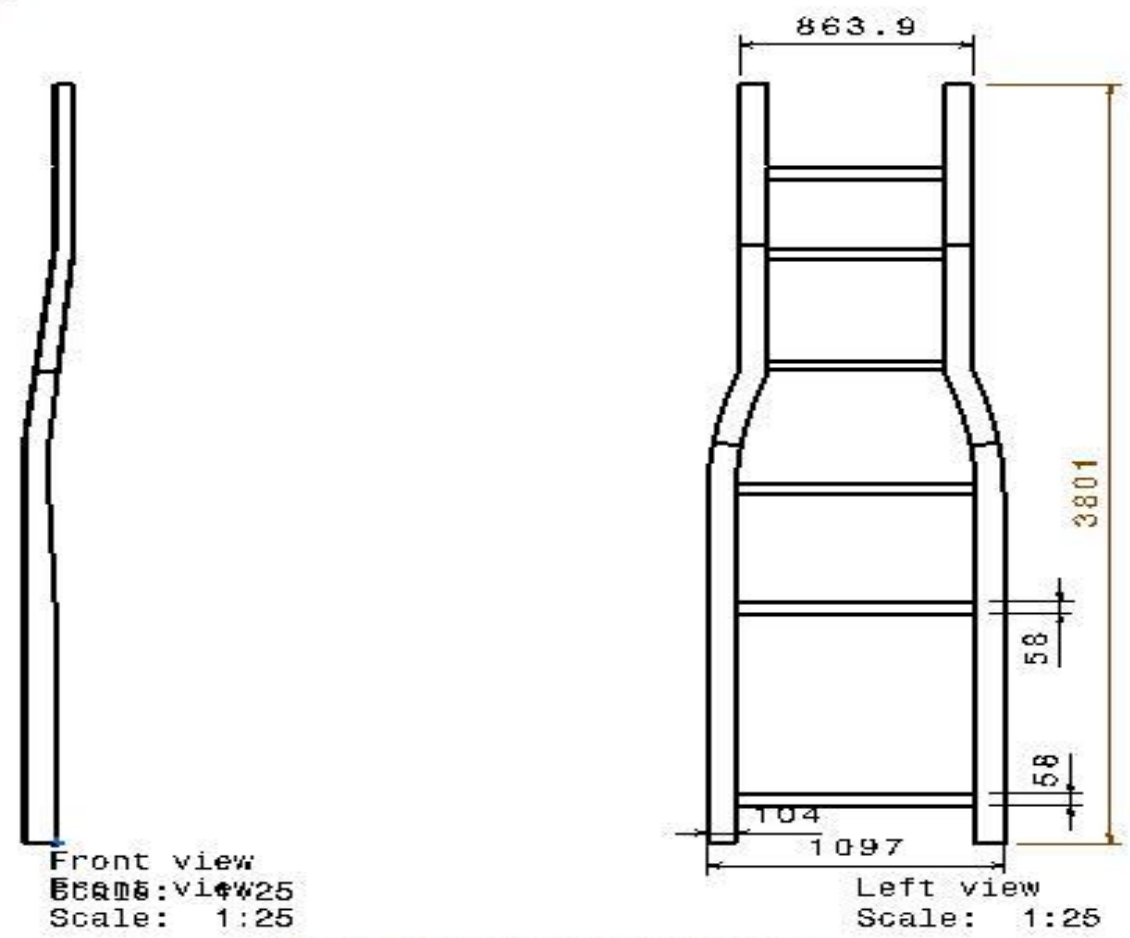

ALL DIMENSIONS ARE IN mm

Fig.1:Draft view of the chassis 


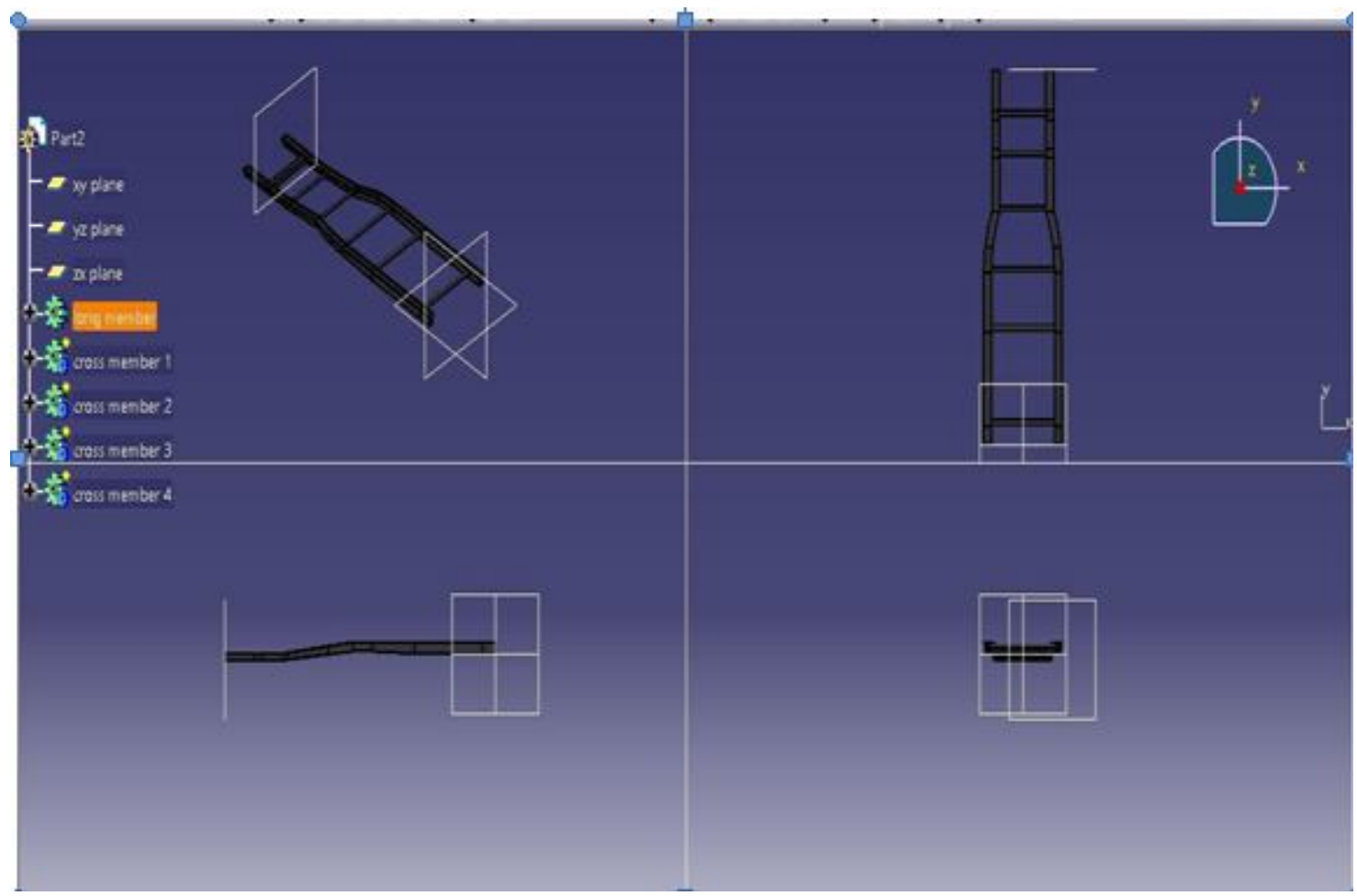

Fig 2 Isometric view of the chassis

Material Details: Structural steel

\begin{tabular}{|c|l|c|c|}
\hline S.No & \multicolumn{1}{|c|}{ Mechanical Properties } & Value & Unit \\
\hline 1 & Young's Modulus & 210 & $\mathrm{GPa}$ \\
\hline 2 & Poisson's Ratio & 0.33 & - \\
\hline 3 & Ultimate Strength & 460 & $\mathrm{MPa}$ \\
\hline 4 & Yield Strength & 250 & $\mathrm{MPa}$ \\
\hline 5 & Density & 7850 & $\mathrm{Kg} / \mathrm{m}^{3}$ \\
\hline
\end{tabular}

Table 2 Weights of components

Methodology-Finite element method

The main aim of the chassis design is capture the static stress and fatigue life of the chassis. As is needed for any finite element analysis, the Governing differential Equation provided by equation of equilibrium

\section{$\mathrm{F}=[\mathrm{K}] \mathrm{U}$}

Where, $[\mathrm{K}]$ is the square matrix, $\mathrm{U}$ is the vector of unknown value; $\mathrm{F}$ is the vector of known concept. Equation (2.1) is the basic finite element equation. The finite element method is used for the solution of static equilibrium of chassis. In order to formulate the problem, the structural deformation and stresses of a chassis can be calculated matrix method. The initial and boundary conditions need to be specified. The appropriate initial condition would be displacement in the chassis applications.

\section{. ANALYSI S IN NASTRAN PATRAN}


The analysis of the truck chassis is taken in the nastranpatran software. In this the analysis is to be done for flange with Uniform cross section

Meshing of truck chassis

The number of elements that are present in the chassis, cross member and the long member are showed in the following tables.

\begin{tabular}{|c|c|c|}
\hline \multicolumn{2}{|l|}{ Long Members } & \\
\hline S.No & Element Type & No. of Elements \\
\hline 1 & Quad 4 & 26322 \\
\hline 2 & Tria 3 & 70 \\
\hline \multicolumn{2}{|l|}{ Total Number of Elements $=\mathbf{2 6 3 9 2}$} \\
\hline \multicolumn{2}{|l|}{ Total Number of Nodes $\mathbf{3 5 8 5 3}$} \\
\hline
\end{tabular}

Table 3 Long member elements

\section{LOAD AND BOUNDARY CONDITIONS}

Load and Boundary condition have to truck chassis section. Boundary conditions have to apply a bottom section. The boundary conditions applied.

Self weight applied as uniformly distributed load (UDL) is applied to the top section of the truck chassis. Load $3.63 \mathrm{~N} / \mathrm{mm}$ applied equally over the length of the chassis.

Long member stress

The stress produced on the chassis with uniform cross section

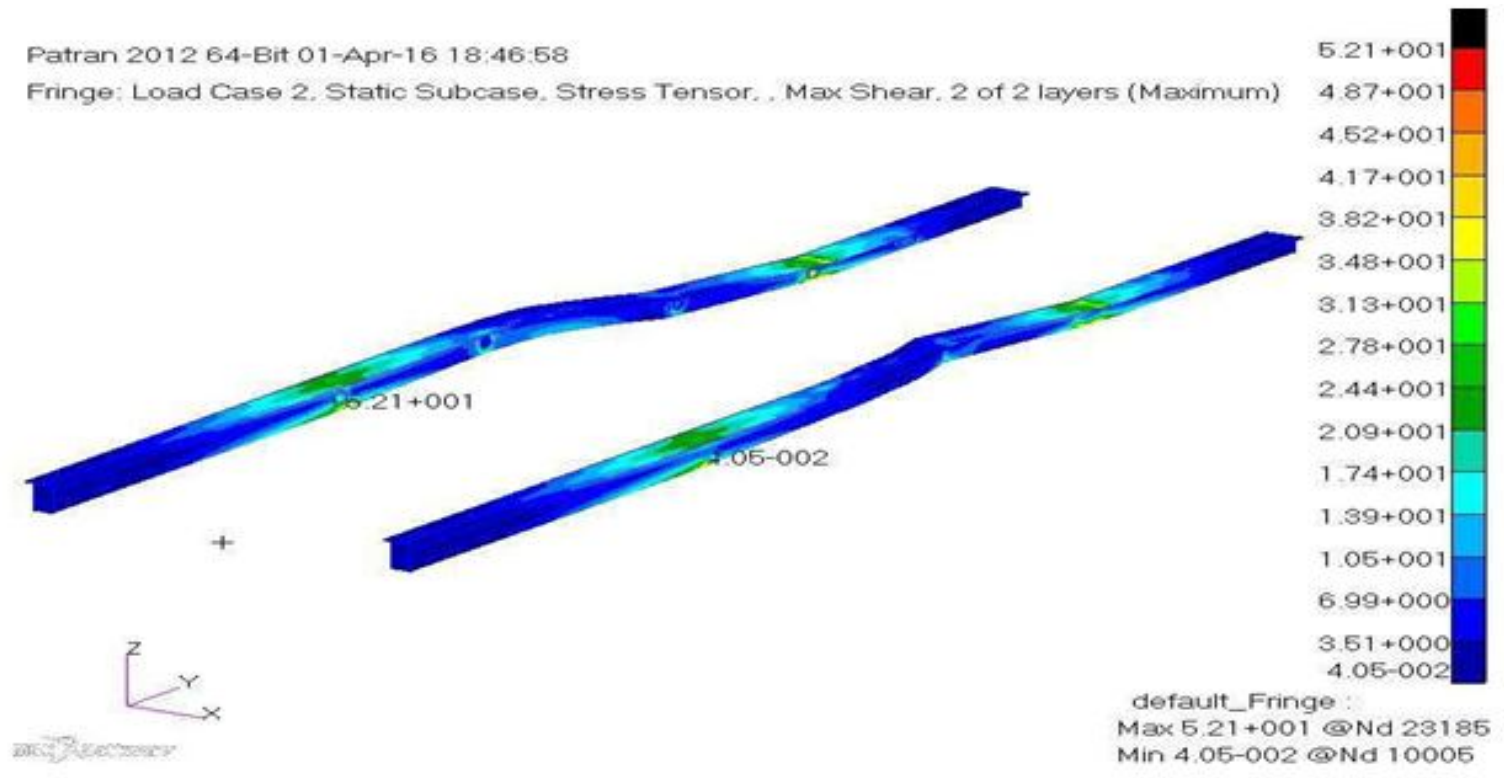

Fig 3 Long member max shear stress 


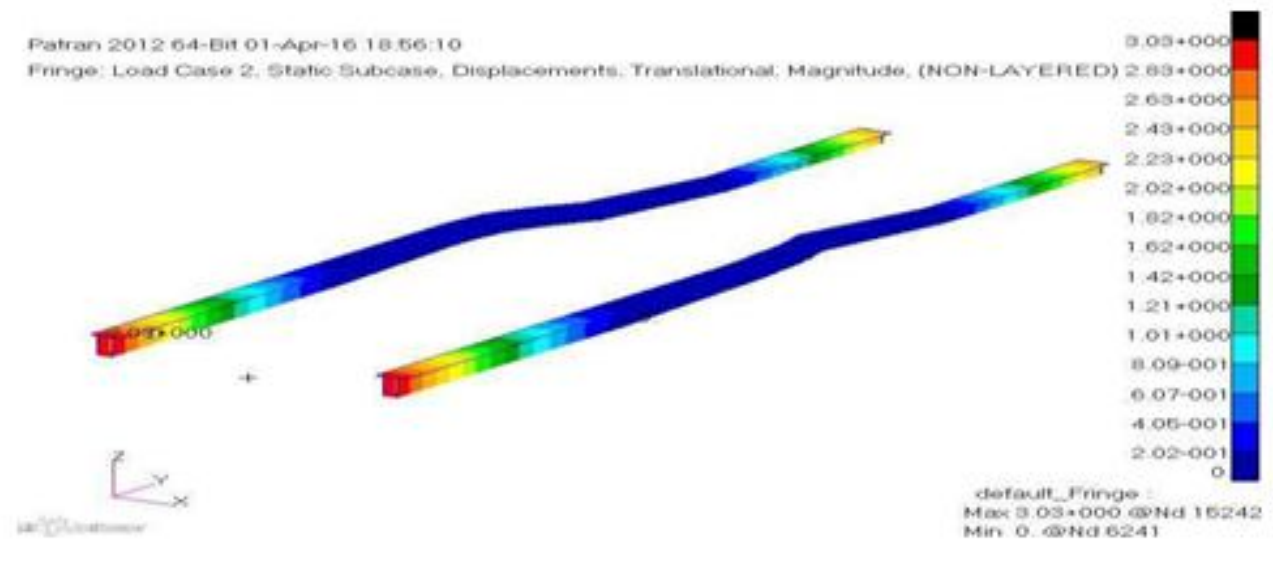

Fig 4 Long member displacement

IV RESULTS

The material used for the analysis is structural steel and the properties of the material is as followed. A measure of strength frequently used in Europe is the RF With the strength and applied loads expressed in the same units

$\mathrm{RF}=$ Proof Strength/Proof Load $=$ Ultimate Strength/Ultimate Load

RESERVE FACTOR VALIDATION

Long members

\begin{tabular}{|c|c|c|c|c|c|}
\hline S.No & $\begin{array}{l}\text { Type of } \\
\text { stress }\end{array}$ & $\begin{array}{c}\text { Ultimate } \\
\text { Strength } \\
\left(\mathrm{N} / \mathbf{m m}^{\wedge} \mathbf{2}\right)\end{array}$ & $\begin{array}{l}\text { Obtained Stress } \\
\quad\left(\mathbf{N} / \mathbf{m m}^{\wedge} \mathbf{2}\right)\end{array}$ & $\mathbf{R F}$ & MOS \\
\hline & Von mises & 469 & 95.6 & 4.9 & 3.91 \\
\hline & $\begin{array}{l}\text { Max. } \\
\text { Principal }\end{array}$ & 469 & 73.8 & 6.4 & 5.4 \\
\hline 3 & Max. Shear & 281.4 & 52.1 & 5.4 & 4.4 \\
\hline
\end{tabular}

Table 4 Uniform thickness long member results 


\begin{tabular}{|r|l|r|r|r|r|}
\hline S.No & Type of stress & $\begin{array}{l}\text { Ultimate } \\
\text { Strength } \\
\left(\mathbf{N} / \mathbf{m m}^{\wedge} \mathbf{2}\right)\end{array}$ & $\begin{array}{c}\text { Obtained Stress } \\
\left(\mathbf{N} / \mathbf{m m}^{\wedge} \mathbf{2}\right)\end{array}$ & RF & MOS \\
\hline 1 & Von mises & 469 & 82.7 & 5.7 & 4.67 \\
\hline 2 & Max. Principal & 469 & 52.4 & 9.0 & 8.0 \\
\hline 3 & Max. Shear & 281.4 & 44.3 & 6.4 & 5.4 \\
\hline \multicolumn{7}{r}{} \\
\hline \multicolumn{7}{r}{ Displacement of long member $=1.82 \mathrm{~mm}$} \\
\hline
\end{tabular}

Table 5 Varying thickness long member results

The stresses produced on the chassis in long member cases are observed in the software and the main things can be observed that is varying thickness of the chassis member is produced the good results compare to the other cases. Hence the stress and the deflection calculated are close to software values i.e. $112.34 \mathrm{MPa}$ and $3.03 \mathrm{~mm}$. the slight deviations in the values are may be because software not able to reproduce actual conditions and simplification of the chassis model. After comparing with the analytical and software results there be a small difference with the results.

\section{CONCLUSION}

Based on the analysis results of the present work, the following conclusions can be drawn.

1)Part is safe under the given loading condition.

2)To improve performance, geometry has been modified which enables to reduce stress levels marginally well below yield limit.

3)The generated Von Misses Stress \& Maximum Shear Stress is less than the permissible value so the design is safe for all three materials.

4)The Rectangular Box Cross-section Type of Ladder Chassis is having least deflection, Von Misses stress and Maximum Shear stress for Steel in all the of three different cross section type of Ladder Chassis.

\section{REFERENCES}

[1] B. Ramya, et.all., A Truck's chassis Frame forms the structural backbone of acommercial vehicle.

[2] Design Data Hand Book 3rd Edition by K.Mahadevan \& K.Balaveera Reddy, 2010

[3] Design of machine elements II by Prof. J.B.K. Das and P.L. Srinivasa Murthy, Sapna book house (P) Ltd., 2010

[4] Pavol, R., D. Kumar, S. Csaba, M. Neil and C. Rey, 2008. Modeling and measurement of granule attrition during pneumatic conveying in a laboratory scale system, Powder Technology, 185: 202-210.

[5] Roark's Formulas for Stress and Strain WARREN C. YOUNG RICHARD G. BUDYNAS, McGraw-Hill, Seventh Edition, 2002.

[6] Shigley's Mechanical Engineering Design, McGraw-Hill, Eighth Edition, 2006

[7] ASME Sec II part D material properties ,ASME,Publish date 2015

[8] Tanveer Ahamed Bankapur,Lohitesh Jaga Kumar,Dr.Irfan G,"Design and Analysis of Dual plate Check Valve",IJIET volume 07, Issue 01,June 2016,pp 422-426 